\title{
TRANSFERÊNCIA DE TECNOLOGIA ENTRE A UNIVERSIDADE E A INDÚSTRIA
}

TECHNOLOGY TRANSFER BETWEEN UNIVERSITY AND INDUSTRY

\author{
Fátima Portela Cysne, Doutora \\ fatticysne@yahoo.com.br ou fatimaportela@hotmail.com \\ Professora Adjunta \\ Departamento de Ciências da Informação do Centro de Humanidades \\ Universidade Federal do Ceará
}

\begin{abstract}
RESUMO
Abordagem conceitual de tecnologia, inovação tecnológica e de transferência de tecnologia entre universidade e indústria como transferência de conhecimento (tácito e codificado), como base teórica que permite incluir os serviços de informação como componente relevante para o sucesso da transferência. Análise do processo de transferência de tecnologia, dos mecanismos, dos atores envolvidos em sua execução e da complexidade de sua implantação.
\end{abstract}

PALAVRAS-CHAVE: Transferência de Tecnologia. Tecnologia. Inovação Tecnológica. Transferência de Conhecimento. Serviços de Informação.

\section{INTRODUÇÃO}

Os estudos sobre desenvolvimento têm mostrado que o crescimento social e o poder das nações são responsáveis diretos pela capacidade de inovação tecnológica e de transferência e aplicação de tecnologia das empresas em cada país. Isto está ficando cada vez mais forte, proporcionado pelo rápido desenvolvimento de modernas tecnologias e por uma prospecção sem precedentes de transferência tecnológica.

Exemplo disso são as redes de informação e comunicação, com base em computadores e internet, como forças motoras da transferência, permitindo que mais facilmente as informações sejam intercambiadas e pretendidas, constituindo-se em um canal potencial de transferência, que junto com os serviços de informação especializados já estão formando uma cadeia online de serviços para dar suporte à inovação e transferência tecnológica: (i) organização, processamento e controle de coleções de informações especializadas; (ii) análise, seleção, filtragem e re-empacotamento de conhecimento científico em informação industrial; (iii) serviços de informação online como link entre o setor científico e produtivo, cujos serviços incluem bases de dados com projetos técnicos, patentes, experts e talentos, e propostas de investimentos. Os serviços de informação estruturados para dar suporte à transferência de tecnologia só podem ser pensados à luz de um melhor entendimento sobre 
tecnologia, inovação tecnológica, transferência de tecnologia (em especial, entre a universidade e a indústria).

Observando-se o cenário atual, não se pode deixar de perceber que o ambiente empresarial está ficando cada vez mais agressivo e as empresas são obrigadas a se tornar competitivas em um mercado cada vez mais global. Isto tem forçado as organizações (privadas e públicas) a investirem em tecnologia, no desenvolvimento do seu capital intelectual, na sua capacidade econômica e social e em sistemas de informação, com vistas a melhorar sua posição de competitividade.

Esses são fatos significativos que dão origem a mudanças fortes e contundentes no comportamento de todas as sociedades, e assim, trazendo constantemente novos desafios para todas as nações, uma disputa econômica e tecnológica que é muito difícil de ser enfrentada por países em desenvolvimento, como o Brasil, requerendo dos mesmos maiores investimentos em tecnologias e inovação tecnológica e a busca de parcerias de transferência de tecnologia, em especial com as universidades.

A transferência de tecnologia, a partir de um estreitamento de relações entre esses dois setores, tendo como objetivo central subsidiar as empresas a se manterem competitivas e ao país um desenvolvimento tecnológico sustentável, tem sido tema central de debate e de extensa pesquisa desde a década de 1950. Isso se dá pela necessidade de se compreender de forma mais vertical o que vem a ser transferência tecnológica, o que ela envolve, o que exatamente está sendo transferido, de que forma e o que é requerido em termos de capacidade de transferência (tanto no ambiente do provedor, quanto do receptor), qual vocabulário produz uma compreensão sem ambigüidade da mesma, que estrutura de transferência deve ser montada para garantir seu sucesso etc.

Contudo, ainda há uma predominância tecnológica nessas abordagens conceituais, produzindo lacunas de discussão sobre componentes importantes do processo de transferência, como a informação e a infra-estrutura necessária ao seu efetivo e satisfatório fluxo, dentro de uma dada instituição ou a transferência de conhecimento entre setores.

O objetivo deste artigo é apresentar uma abordagem conceitual mais holística de transferência de tecnologia (como transferência de conhecimento incorporado em pessoas conhecimento tácito - em produtos e serviços -tecnologia - documentos técnicos e científicos - conhecimento explícito - que requer uma infra-estrutura de serviço de informação) como um extrato da base teórica usada na tese de doutorado da autora para discutir os serviços de 
informação como canais de transferência de tecnologias que são omitidos ou negligenciados no debate atual sobre transferência tecnológica.

O foco do artigo, assim, será nessa abordagem mais dinâmica de transferência de tecnologia como transferência de conhecimento de mão dupla que inclui todos os elementos envolvidos no processo de transferência, como o know-why (princípios que subjazem a tecnologia), o know-how (entendimento da tecnologia e do seu funcionamento), conhecimento incorporado nas pessoas, o conhecimento explicitado em documentos técnicos e científicos, as práticas organizacionais, o aprender fazendo, imitando, a capacidade e competência das empresas transferidoras e receptoras de tecnologias, assim como os canais e a infra-estrutura necessários ao sucesso da transferência.

\section{TECNOLOGIA E INOVAÇÃO TECNOLOGICA}

Esta seção versa sobre tecnologia e inovação tecnológica como uma introdução necessária ao entendimento do processo de transferência de conhecimento entre a universidade a indústria.

Tecnologia e inovação não são necessariamente as duas faces de uma moeda, embora estejam estreitamente ligadas. Uma tecnologia pode se apresentar de diferentes formas; pode ser um produto tecnológico (tangível), um processo tecnológico (método intangível) ou em um tipo incorporado no outro (tangível e intangível), um conhecimento ou um modelo conceitual pronto para ser produzido (conhecimento explicitado em patentes, relatórios de pesquisa aplicada, manuais etc.). Trabalhar com a tecnologia tangível é bem mais simples do que tratar do intangível que está incorporado em um produto, processo etc., como por exemplo, o computador com um sistema de controle que pode estar incorporado em um processo de desenvolvimento de programa.

Volti, em seus estudos de 1995, sugeriu que embora a palavra tecnologia seja relativamente nova (termo usado inicialmente por Jacob Bigelow em1920), a dependência da tecnologia é tão velha quanto a raça humana. Etimologicamente, techne vem tanto do grego, significando arte, técnica ou habilidade, quanto do teks do Indo-Europeu e significa tecer ou fabricar. Assim, tecnologia pode ser considerada um elemento cultural, ao se considerar que é a capacidade humana de criar tecnologia que torna homem diferente de outros animais. Só o homem tem a habilidade para ampliar seu ambiente natural através do desenvolvimento e uso da tecnologia. A raça humana tem desenvolvido tecnologias para auxiliá-la na produção de 
coisas que de outra forma não poderiam ser feitas e sua sobrevivência tem sido assistida por ferramentas e técnicas criadas pelo homem para esse fim.

Esses são, essencialmente, conceitos de tecnologia que apresentam algumas características básicas interessantes para o pretendido neste estudo: (i) o desenvolvimento de tecnologia requer um esforço de grupo que sugere trabalho em organizações, (ii) embora um indivíduo possa entender como uma determinada tecnologia opera, para fazê-la funcionar é necessário que mais de uma pessoa trabalhe em cada um dos seus componentes-tarefas; (iii) a tecnologia, como um sistema, requer o suporte de diferentes componentes, como uma infraestrutura organizacional, equipamentos, pessoas com habilidades específicas etc.

ALMEIDA (1981) descreve a tecnologia, em linhas gerais, como um processo que envolve os setores de ciência, de engenharia, de tecnologia, de produção e comercialização e de divulgação: nasce no setor que produz ciência (universidade), tem avanços nas aplicações científicas nos institutos de pesquisa, é projetada como produto, processo e serviço pelas empresas de engenharia. As matérias-primas e os equipamentos para o desenvolvimento do bem final são produzidas por empresas específicas; outras empresas utilizam os bens de produção e os projetos de seu processo para produzir a tecnologia que será comercializada e entregue ao consumidor final.

Uma definição linear de tecnologia a considera como um sistema baseado em aplicação de conhecimento que se manifesta em objetos físicos ou em formas de organização com o objetivo de alcançar metas específicas. Porém, nem sempre isso é verdadeiro, tendo em vista que também se desenvolvem tecnologias sem objetivar a satisfação de necessidades existentes. Muitos exemplos apresentados na literatura sobre o tema mostram que tanto há invenção tecnológica em busca de problemas para resolver, como há também novas tecnologias que criam novas necessidades.

É ainda Volti (1995, p.7), quem declara que: "o desenvolvimento de tecnologia é um processo inerentemente dinâmico e cumulativo". Ele observa que esta característica de progresso dinâmico da tecnologia faz com que ela seja um 'endeavour' humano sem igual: só o ser humano é capaz de fazer as coisas melhor e mais rapidamente, produzindo mudanças em um dos contínuos avanços da tecnologia existente. Dessa forma, a tecnologia representa um tipo sonho humano de progresso ininterrupto, que é complexo e que só pode ser entendido no contexto de um determinado jogo de valores e de convicções culturais.

As filosofias de Volti sobre tecnologia consideram-na como (i) uma metáfora da noção humana de progresso contínuo, que tem caracterizado o modo como as pessoas 
pensam sobre elas mesmas e sobre seu mundo. Ele sugere que a avaliação (feedback) seja o princípio da tecnologia, concebendo-o como um método de controle de um sistema que reinsere os resultados de seu desempenho anterior"; (ii) um princípio de avaliação (feedback) que tem sido considerado um dispositivo de regulagem, que quando usado ajudará a um sistema desregulado a obter seu equilíbrio, e que era incorporado em outras áreas de vida social - o mercado de valores; (iii) uma abordagem racional - a tecnologia tem dado ao ser humano a crença de que o progresso é uma parte natural da vida. Uma sociedade tecnologicamente progressiva é aquela na qual os problemas são observados de modo sistemático e, mais importante, as soluções para problemas são possíveis; (iv) "uma abordagem racional para solução de problema (problem-solving) - está continuamente preocupado com a identificação e desenvolvimento de meios apropriados pelo alcance de objetivos específicos" (p.12). Os modelos racionais de pensamento não conferem superioridade moral. Na realidade, "o pensamento racional extremo pode resultar em grandes transgressões morais" (por exemplo, o nazismo alemão - p.10). "Uma abordagem racional para a solução de problema (problem-solving) está continuamente interessada na identificação e no desenvolvimento de meios apropriados para o alcance de fins particulares". (p. 12).

Os processos de pensamentos racionais também levam a uma relutância em se admitir que há alguma coisa capaz de uma posição com escrutínio lógico e empírico.

Com o progresso da ciência e da tecnologia, o homem deixou de acreditar em
poderes de magia, em espíritos e demônios; ele perdeu seu senso de profecia e,
acima de tudo, o seu senso de sagrado. A realidade tem ficado chata, monótona e
utilitária, deixando um grande vazio nas almas dos homens que eles buscam encher
com atividade estressante e por vários dispositivos e substitutos . (FREUND- p.
12).

Há uma suposição de que aquele que tem controle e entende de tecnologia tem de importância fundamental porque é quem tem autoridade para dizer se uma determinada tecnologia está ou não disponível para as pessoas. De modo oposto, a falta de conhecimento tecnológico pode tornar uma pessoa impotente diante da tecnologia. Este pensamento está relacionado com a competência racional que requer frieza de objetividade e imparcialidade. Assim, tem que se estar atento a esta questão na porque o nível de conhecimento tecnológico dos tomadores de decisão pode trazer tanto tecnologias que não são compatíveis com os valores e as convicções sociais de uma determinada sociedade, como tecnologias modernas que são acessíveis, de alguma forma, pela população inteira. (VOLTI, 1995). 


\section{INOVAÇÃO TECNOLÓGICA}

Quando se fala em inovação não se está referindo sempre a uma nova tecnologia ou ao resultado de uma invenção, mas a algo que as pessoas, as empresas ou o sistema social percebem como novo (SPENCE, 1994). Assim, entende-se por inovação algum produto ou processo que está sendo colocado para uso pela primeira vez em uma organização ou em um sistema, não importando se é uma tecnologia nova ou velha. Por exemplo, se no sertão cearense forem utilizadas energia e tecnologias para irrigação, aragem e processamento da cana de açúcar para a produção de rapadura e outros derivados, não há necessidade de se utilizar uma tecnologia de última geração para se dizer que houve inovação nessa região sertaneja.

O processo de inovação tecnológica envolve uma gama de fases, passos e atividades que vão se expandindo a partir da geração de novas idéias, através de aplicações práticas bem sucedidas dessas mesmas idéias; a transferência tecnológica entre organizações ou indivíduos é apenas uma parte do processo, muito embora em algumas situações, seja sua parte crítica. Este processo constitui o contexto maior no qual os programas de transferência de tecnologia necessariamente têm que operar; isto se a meta for transformar novos conhecimentos e novas tecnologias em produtos competitivos no emergente mercado global.

Para desenvolver e melhorar programas, priorizar atividades tomar decisões estratégicas e operacionais que sejam ao mesmo tempo apropriadas e efetivas, é essencial que se tenha um entendimento básico dos princípios e questões envolvidos no processo total de inovação. Do ponto de vista econômico, pode-se dizer que uma transferência de tecnologia que não resulte em comercialização bem-sucedida é considerada de pouco valor. A literatura que versa sobre o processo total de inovação (e outras questões a ela relacionada) tem enfatizado que a iniciativa federal de transferência de tecnologia é crucial para facilitar o rápido avanço do progresso tecnológico, assim como para aumentar a competitividade econômica nacional. (SANDIA) (1991).

O domínio tecnológico e a criação transcendem a tecnologia e a dependência das pessoas (à tecnologia). O século que findou presenciou um rápido desenvolvimento de inovação no qual a tecnologia parece que passou a ser uma força central dos processos sociais. Tecnologia e conhecimento tecnológico se tornaram componentes essenciais de desenvolvimento que podem, se bem usados, assegurar à humanidade a mais alta qualidade de vida em termos de produção de riqueza, de poder e de domínio da natureza. O problema é que 
começam a considerar a tecnologia como um fim em si mesma e como uma extensão das próprias pessoas. Isto ocorre porque a tecnologia cria uma teia infra-estrutural na qual as pessoas e as técnicas que elas criam podem ser totalmente envolvidas nessa rede.

Isto é motivo de reflexão, algo com que se preocupar, porque há possibilidade de haver uma frustração paradoxal dos valores humanos, quando se dá à tecnologia um poder que ela não tem, de domínio das pessoas, ocasionando a chamada tecnocracia que realmente pode ameaçar a existência humana. A visão que se deve disseminar da tecnologia é a de um instrumento criado pelo homem para satisfazer as necessidades humanas, e, por isto mesmo, deve estar voltada para suprir os valores e a autonomia humanos. Esta perspectiva requer uma rejeição da tecnologia como auto-suficiente, e uma compreensão delas como de dimensão/base humanas, assim como as artes, as habilidades etc., criadas pelo e em função do homem, podendo, deste modo, produzir a requerida relação homem/máquina, controle e espontaneidade. (DREYFUS, H.; DREYFUS, S, 1986; GILL, 1996).

Essa abordagem é importante para o desenvolvimento do que deveria ser uma tecnologia apropriada: - uma maturidade de relações recíprocas entre as pessoas, a tecnologia e o mundo. Isto implica numa reflexão sobre valores e metas que antecede o desenvolvimento de novas tecnologias, a preservação da diversidade, a promoção da interação entre as pessoas, as técnicas e o ambiente; geração e uso de tecnologia, recursos equilibrados, e promoção de desenvolvimento humano pelo uso de técnicas.

Volti (1995) identifica quatro níveis de inovação: (i) modificação tecnológica - que implica em um desenvolvimento gradual das tecnologias existentes; (ii) hibridização tecnológica - significando uma combinação de novas tecnologias com as já existentes; (iii) mutação tecnológica - transformação de tecnologia para outra forma ou para outro propósito; (iv) domínio e criação tecnológicos - o nível mais alto de inovação, que implica em uma transcendência da tecnologia e da dependência das pessoas dela (tecnologia).

Nas novas perspectivas de inovação tecnológica regional ou nacional, mais do que a acumulação de capital e infraestrutura, a tecnologia e a criação constituem a real máquina de desenvolvimento econômico. A inovação tecnológica constitui-se em um processo complexo, dinâmico e coletivo que envolve muitos atores (sociais, tecnológicos e econômicos), como pesquisadores, organizações e governo. O sucesso de inovação depende fortemente da capacidade desses diferentes agentes de desenvolver e aplicar novos conhecimentos.

Então, hoje há uma ampla discussão sobre a necessidade de melhorar as interações institucionais e sua eficiência dinâmica para produzir e disseminar coletivamente informação, 
conhecimento e habilidades específicas, construindo uma capacidade regional para inovação. Contudo, vários são os obstáculos que têm tornado difícil produzir e extensamente difundir conhecimento tecnológico em setores diferentes, como por exemplo, (i) a demanda reduzida de empresas interessadas em apoio externo para inovação em relação à Pesquisa e desenvolvimento (P\&D); (ii) a pouca colaboração entre os setores público e privado; (iii) a ênfase em apoio para $\mathrm{P} \& \mathrm{D}$ em instituição pública, pouco preocupada com outras atividades tais como consultoria, ajuda técnica, serviços de informação científica e tecnológica, assim como projetos centrados na adoção e difusão de tecnologia.

Um modelo linear de desenvolvimento de tecnologia, que tem promovido o desenvolvimento de infra-estruturas tecnológicas e projetos de P\&D, aumentando a capacidade de uma companhia (ou país) para produzir e acumular conhecimento e habilidades, não tem propiciado a difusão e a utilização de conhecimento prático. Este é um aspecto muito importante do desenvolvimento de inovação, que pode transformar os conhecimentos científicos e tecnológicos em lucro econômico e social.

Para isto, um sistema e um serviço de informação local, regional e nacional pode desempenhar um papel fundamental. Ele pode produzir uma efetiva e racional utilização dos recursos existentes, acrescentados à acumulação de habilidades, através de programas de $\mathrm{P} \& \mathrm{D}$, que requer serviços de informação que sejam orientados para a empresa para abordar as atividades transferência de tecnologia a partir do mercado das reais necessidades (needs) das empresas, e das solicitações e interesses (wants) da sociedade ${ }^{1}$.

Esta análise realça fraquezas e forças dos sistemas local, regional e nacional de inovação. A inovação, considerada como um sistema, requer diferentes atores (como as instituições de ensino superior e pesquisa, estabelecimento público de desenvolvimento científico e tecnológico, instituições privadas sem fins lucrativos de $\mathrm{P} \& \mathrm{D}$, companhias de grande porte, pequenas empresas de base tecnológica, financiando consorciados para inovação e transferência de tecnologia, serviços de apoio empresariais etc.), que têm diferentes níveis de interesses (wants) e necessidades (needs) de informação, o que deveria ser considerado em qualquer serviço de informação.

\subsection{Tecnologias Inovadoras}

As modernas tecnologias, como a mais singular fonte de crescimento econômico, apresentam algumas características: (i) progresso contínuo e tipicamente consciente, com movimento sem equilíbrio (soluções tecnológicas se tornam novos pontos de partida); (ii) 
uma rápida expansão e alcance global; (iii) circularidade de fins/significados (novas tecnologias produzem novas necessidades e desejos); (iv) dreno de recursos (multiplicação de bens e o crescimento de aparato tecnológico); (v) artificialidade, abstração (técnicas que satisfazem os sensos e a mente); (vi) crescimento da tecnologia eletrônica para a informação eletrônica; (vii) a questão da obsolescência do homem (as relações entre automação e trabalho, inteligência artificial e tomada de decisão); e (viii) produção de tensão na própria Natureza.

Como característica da ciência e da tecnologia no século 20 tem-se a tremenda expansão e consolidação do alojamento (incubação) de atividades científicas e tecnológicas em uma extensa rede de organizações formais, firmemente estabelecidas e de médio e grande porte. A forma ativa das características de produtos tecnológicos, por um lado, é especialmente a complexidade do sistema (muitas partes e arranjo hierárquico): (i) estabelecimento (incluindo sistemas de apoio social e técnico); (ii) especialização da produção de falta de produção de sentido; (iii) procedimentos técnicos formalizados (o qual se torna um produto de domínio comparado às técnicas), e (iv) análise de sistemas sociais e tecnológicos.

Por outro lado, as formas ativas das características dos produtos científicos são abstratas e dependentes de teorias e de crescimento. Estas atividades são fixadas pela institucionalização, estrutura organizacional, associações formais/profissionais, e treinamento formalizado. A tecnologia pode produzir tanto pequenas mudanças, como mudanças massivas que, distintamente, afetam a economia. A tecnologia tem, pois, aspectos positivos e negativos. Como uma força subversiva, as mudanças tecnológicas podem produzir modificação ou destruição de papéis sociais estabelecidos, relacionamentos e valores, podendo destruir empresas obsoletas.

A tecnologia é, assim, usada para buscar solução para muitos problemas, tais como a produção de cintos de segurança e bolsa de ar para prevenir acidentes de carro. A literatura tem indicado quatro níveis de desenvolvimento das tecnologias: (i) modificação tecnológica: melhoria gradual; (ii) hibridização tecnológica: combinação de tecnologias existentes; (iii) mutação tecnológica: transformação de uma tecnologia em outra forma ou para outro propósito.

\section{TRANSFERÊNCIA DE TECNOLOGIA ENTRE A UNIVERSIDADE E INDÚSTRIA}

O processo de transferência de tecnologia e as interações entre universidade e indústria têm sido assuntos de extensa pesquisa por fazer parte do atual debate sobre 
desenvolvimento e inovação tecnológica. Os objetivos das pesquisas englobam a compreensão das barreiras, lacunas e limitações do processo de transferência que ocorre entre setores ou países. A meta é desenvolver um vocabulário sem ambigüidades e uma estrutura conceitual para obter um melhor entendimento do que seja determinada transferência, compreendendo sua natureza, processo, o que envolve e o que é requerido do provedor e do receptor de tecnologias.

Nas mais das vezes, a discussão sobre transferência de tecnologia está ainda a desejar por apresentar uma visão predominantemente tecnológica que não inclui alguns elementos componentes e/ou facilitadores da transferência. Exemplo deles: o processo de comunicação, as diferenças nos aspectos culturais e de capacidade entre provedores e receptores, a informação explicitada em patentes, documentos científicos e manuais e a infra-estrutura de serviço, adequação tecnológica etc. Essa abordagem linear tem negligenciado, em especial, a análise de serviços de informação ou os tem subestimado como um pertinente canal que deve ser considerado em qualquer discussão sobre transferência de conhecimento e interações entre a universidade e a indústria.

A pesquisa de doutorado que originou este artigo desenvolveu uma análise do papel desse negligenciado elemento, a partir de uma concepção mais holística de transferência de tecnologia. A abordagem incluiu tanto experiência ou o saber fazer (know-how), como o saber porque (know-why), ou seja, o conhecimento da natureza e dos princípios que subjazem à criação, produção e desenvolvimento de uma dada tecnologia), informação científica e tecnológica, as práticas de trabalho organizacional, a cultura empresarial, as capacidades dinâmicas das empresas de base tecnológica, os processos de comunicação e os serviços de informação como determinantes do sucesso da transferência tecnológica.

O objetivo foi descobrir no processo de transferência de tecnologia, através de uma análise das necessidades de informação de uma empresa e de seu comportamento na busca e nos usos de informação, a existência e/ou os níveis de importância dados aos serviços de informação pelas empresas de parques tecnológicos. O interesse principal foi trazer para o debate sobre inovação e transferência de tecnologia os serviços de informação como canaischave de transferência. Este artigo, dada a abrangência da discussão e observando o espaço de sua extensão nesta revista eletrônica, está limitado à uma abordagem conceitual de transferência de tecnologia, incluindo análises mais gerais de tecnologia e inovação tecnológica. 


\subsection{O Processo de Transferência de Tecnologia}

Transferência de tecnologia, como um processo inserido no contexto da história da própria história, teve na Revolução Industrial o seu primeiro grande destaque ao provocar um fluxo significante de novas tecnologias de uma pequena, mas influente nação, a Inglaterra, para a indústria de três grandes economias e sistemas políticos: Européia, Americana e Russa. A expansão das atividades industriais pela transferência da produção tecnológica continuou através do Século 19, atingido um grande desenvolvimento na segunda metade do século passado, que vem aumentando cada vez mais no início deste Século XXI.

A alavanca destas transferências tem sido a ampla disseminação de novas tecnologias de fabricação local (doméstica) e a crescente (mesmo que limitada em sua extensão) exportação que permanece como norma. A partir dos anos 1970, e intensificado na década de 1980, as operações de produção fora da costa aduaneira dos países têm sido de grande interesse do setor industrial. Uma prioridade clara tem recaído nos fatores de insumo de baixos custos ou nos novos mercados. (JEREMY,1992; GRANT; STEELE, 1995).

A existência de um corpo crescente de literatura e de extensa pesquisa sobre a complexidade do processo de transferência de tecnologia demonstra ser este um tema de grande interesse para os países desenvolvidos e em desenvolvimento. A contribuição que a tese dá ao atual debate sobre o processo de transferência, diz respeito a um melhor entendimento do que exatamente a transferência tecnológica consiste, buscando explicitar o que está sendo transferido ou identificar o que limita ou impede a transferência de uma dada tecnologia ou processo tecnológico. Considera-se ser um aporte relevante para explicitar o conteúdo da transferência tecnológica e os modelos dos processos nela envolvidos e, assim, poder proceder à análise de inteireza, complexidade e elementos (por exemplo, a verificação da eficácia dos vários métodos, mecanismos e canais de transferência). Esta foi a razão da escolha desse item da tese para sua divulgação em periódico científico.

Para além da simples transferência de tecnologia, os estudos atuais mostram uma preocupação em que ela seja apropriada, o que a torna mais que um processo: constitui-se em um investimento de pesquisa que assegura que o reembolso da aplicação oportuna da imissão da pesquisa seja derivado do uso dos produtos dela advindos. Esse processo de transferência de tecnologia apropriada encontra eco nessa concepção mais holística de transferência por ser um processo de comunicação que tem base no planejamento estratégico, em marketing de pesquisa, de produção e de venda e na elevação do capital intelectual dos investidores, produtores e usuários da tecnologia. 
Por marketing de transferência de tecnologia apropriada, entende-se a oferta ou a provisão fundamental ou ainda o elemento de transferência que exige conhecimento detalhado dos consumidores e dos produtos. Transferência de tecnologia apropriada é um sistema que requer certas habilidades, como o domínio das técnicas de gerenciamento e de comunicação, que podem ser aprendidas em cursos acadêmicos tradicionais, em seminários supervisionados ou em programas de aprendizagem organizacional que tem base na educação continuada, na transferência de conhecimentos tácito e explicito e nos projetos das comunidades de práticas.

\subsection{Concepções de Transferência de Tecnologia}

Há diferentes concepções de transferência de tecnologia (TT), variando de uma abordagem muito linear para uma perspectiva mais holística. Para este estudo se optou por uma concepção dinâmica de TT que a define como um processo de comunicação de duas mãos pelo qual, duas partes (o provedor e o receptor) trocam conhecimento, e no qual a aquisição, o entendimento, a absorção e a aplicação de tecnologia pelo receptor ocorre de forma objetiva e com sucesso.

Sábato (1978) define tecnologia como um conjunto ordenado de todos os conhecimentos sistematizados na produção, distribuição e uso de bens e serviços.

Autio (1993) afirma que o conceito de transferência de tecnologia tem sido usado pelo menos desde do início dos anos 1970 e que a maioria dessas definições de TT, em todo o mundo, é muito limitada em seu próprio escopo. Para o autor, há necessidade de maior precisão dos conceitos de transferência de tecnologia em relação à sua classificação horizontal ou vertical, como por exemplo, a transferência internacional de tecnologia:

\footnotetext{
Uma falta de entendimento geral é comparar transferência de tecnologia com 'transferência internacional de tecnologia entre países desenvolvidos e em desenvolvimento'. Neste último caso, transferência de tecnologia é vista de forma estreita [míope], como a transferência de um determinado 'hardware' do usuário original para um conjunto de usuários.
}

$\mathrm{O}$ autor oferece uma definição mais abrangente de transferência reportando-a um processo ativo no qual a tecnologia ultrapassa as fronteiras de duas entidades - sejam estas países, companhias ou até mesmo pessoas, dependendo do ponto de vista do observador. Concebendo a TT como um processo social e uma interação ativa entre duas ou mais entidades sociais, o autor reconhece que nela se processa a soma de conhecimentos tecnológico, que são aumentados pela transferência de um ou mais componentes tecnológicos.

A transferência de tecnologia tem sido também definida como um processo de transferência de descobertas científicas e tecnologias desenvolvidas em projetos acadêmicos 
ou em laboratórios ou agências governamentais, para a comunidade industrial e não governamental. A meta tem sido a otimização da competitividade dos países no mercado mundial, assegurando que as inovações tecnológicas de seus laboratórios beneficiem os contribuintes e as inúmeras indústrias que compõem sua base industrial e um caminho fundamental para os países em desenvolvimento responderem aos desafios e exigências postos hoje pelo mercado crescentemente global.

Bessant e Rush (1993), definem transferência de tecnologia como um conjunto de atividades e processos por meio do qual uma tecnologia (embutida ou 'personificada' nos produtos, em novos processos ou ainda em forma explicitada de conhecimentos, habilidades, direitos legais, etc.) é passada de um usuário a outro, também podendo ser indivíduos, organizações ou países.

Rogers (1995), entende a transferência de tecnologia como o processo em que uma inovação é comunicada através de um sistema social e como o estudo do fluxograma da tecnologia, desde que é criada até sua adoção para implementação e a verificação de eventuais efeitos.

Estes conceitos de transferência de tecnologia requerem, de alguma forma, a aprendizagem e adaptação por parte da organização receptora, que pode ocorrer pelo fazer ou pelo uso (o que tem sido abordado nas teorias de learning by doing - aprender fazendo - e learning by using - aprender usando) ou pelo estudo dos documentos técnicos e da literatura científica e tecnológica, em relação a uma determinada tecnologia ou transferência tecnológica. Isto inclui a aquisição de conhecimento experimental (empírico, pragmático), habilidades pessoais e técnicas, criatividade e perícias (expertise) ${ }^{2}$, idéias técnicas, documentos, informações e $\operatorname{dados}^{3}$, equipamento, protótipos, designs e códigos computacionais ${ }^{4}$.

Outras definições, também incluídas neste estudo, conceituam TT como um processo por meio do qual um novo conhecimento ou uma nova tecnologia, gerados em laboratórios de pesquisa ou universidades, são ainda mais desenvolvidos e comercialmente explorados pelo setor privado doméstico, como também são aplicados e apropriados pelos Governos Federal, Estadual e Municipal (CARR, 1997; REBENTISH, 1993). Nesse caso, a transferência tecnológica é entendida como a soma dessas atividades que conduzem à adoção de novas técnicas de desenvolvimento de produtos e serviços. Como tal, ela inclui a disseminação de informações através das publicações de pesquisa, da consultoria, do treinamento, das feiras científicas, tecnológicas e comerciais, dos seminários, cursos e workshops. 
A transferência de tecnologia em sua compreensão mais vertical é, porém, um processo demorado e complexo, de grande envolvimento, ativo, e tem como meta última, propiciar a incorporação das técnicas como um modo (aceito) de desenvolver funções rotineiras ou de resolver problemas cotidianos de uma forma mais moderna, prática, rápida e eficiente.

A transferência de tecnologia também é vista como uma parte vital da missão da pesquisa em uma organização. De forma crescente, a ênfase está sendo dada no intercâmbio de idéias, habilidades, experiência (know-how) e conhecimento entre a base de ciência e a indústria. Transferência de tecnologia, assim, é vista como um instrumento que assegura o retorno econômico para o capital investido em pesquisa. (GOVERNMENT WHITE PAPER, 1993).

A partir da década de 1990, transferência de tecnologia é abordada como transferência de conhecimento, especialmente o chamado know-why (conhecimento dos princípios e natureza da tecnologia e de sua transferência) e know-how (experiência em como fazer). Faulkner (1994) sugere que transferência de tecnologia inclui a transferência de uma combinação de conhecimentos tácito, prático e codificado (explícito). Outros estudos argumentam que o conhecimento tácito desempenha um papel mais central que o conhecimento formal no processo de inovação (SENKER, 1991; FAULKNER; SENKER; VELHO, 1993; PATEL; PAVITT, 1995). Neste caso, quando houver uma transferência de máquinas ou processos, a transferência de conhecimento ocorrerá pelo 'aprender usando' e 'aprender fazendo' e 'aprender através de imitação' [learning by using e learning by doing, já mencionados, e learning by imitation (aprendizagem pela imitação), uma outra perspectiva da aprendizagem na organização, já apresentada por Rosenberg, em 1982].

São, também, desse período, as concepções que enfatizam o compartilhamento de tecnologia, mais especificamente a troca de conhecimento tácito, muito embora se reconhecendo sua complexidade, por não ser facilmente imitado e/ou transferido através das empresas (WHISTON, 1992; POLANYI, 1966). Como os princípios que subjazem a tecnologia (por exemplo know-how e know-why) não são freqüentemente explícitos, o processo de aprendizagem requer treinamento intensivo, extensivo ou o movimento de pessoas (do setor de pesquisa para o setor produtivo - movimento do conhecimento tácito). Esta limitação na transferência de conhecimento requer atenção dos envolvidos no processo, e mais especificamente dos diferentes departamentos de um firma ${ }^{5}$. 
Atualizando a revisão de literatura sobre o que significa transferência de tecnologia observou-se que o já batido clichê conceitual que define TT como uma atividade pessoa a pessoa, é uma definição precisa; em qualquer transferência é requerido contato entre pessoas na medida em que as invenções e as novas tecnologias provêm e residem na mente humana, ou seja, são em essência conhecimento tácito. Esse tipo de conhecimento pode, em parte, ser explicitado em descrições escritas, em exemplos e nos trabalhos com os protótipos.

Muito embora se tenha notado uma tendência na utilização de outras terminologias com o sentido de TT, como 'desenvolvimento de tecnologia', 'uso de tecnologia', 'colaboração tecnológica', elas não contribuem para aumentar o entendimento do significado de transferência de tecnologia. Este engloba um campo tão amplo de atividades impossível de ser captado em uma definição geral de TT, muito embora mais fácil de ser expresso por definições operacionais e melhor explicitado em mecanismos específicos de transferência.

Extraiu-se alguns exemplos da vasta gama de definições mais modernas de TT para ilustrar esta atualização conceitual, como dados a seguir.

CORTI (1997, apud PERUSSI FILHO, 2001) define tecnologia como uma união coerente e auto-suficiente do necessário conhecimento técnico e organizacional através do qual quem possui esse conhecimento realiza no todo ou em parte seu objetivo operacional, dando centralidade ao uso do conhecimento para realizar uma ação e não a sua posse.

O curso The Washington Area Chapter of the Technology Transfer Society (2005), define TT como o processo de transferir os instrumentos, métodos e dados recentemente desenvolvidos para as mãos daqueles que podem se beneficiar da aplicação da tecnologia ou irá enviá-la para a comercialização”. A The Technology Transfer Society compreende a TT como uma estratégia para alcaçar objetivos, como um processo que leva a atual transferência e como uma disciplina que envolve uma multipicidade de habilidaddes. ROOD (2001) define TT como processo pelo qual o conhecimento, as facilidades ou as capacidades desenvolvidas com financiamento federal de $\mathrm{P} \& \mathrm{D}$ são utilizados para preencher as necessidades dos setores públicos e privados. Michael Odza, editor do Technology Access Report define TT como

"transações ou processo, como as licenças de patentes ou as empresas de base tecnológica, através das quais inovações são mudadas de uma local (como uma univesidade), desenvolvem estágio ou são aplicadas em outro local (como uma empresa) com um propósito comercial $[\ldots]^{\prime}$. 


\subsection{Complexidades da Transferência de Tecnologia}

Todavia, se reconhece que a transferência de conhecimento científico e tecnológico não é fácil. Geralmente o conhecimento produzido por universidades e laboratórios de pesquisa é registrado em um formato e linguagem difíceis para as empresas decodificarem de modo a absorverem e utilizarem. Embora a literatura sobre o tema enfatize a importância de informação científica e tecnológica -ICT para a melhoria do processo de inovação em países em desenvolvimento, a maioria das empresas de base tecnológica, estudadas na pesquisa do doutorado informaram não contar com pessoas qualificadas para filtrar, re-empacotar e gerenciar esses recursos de informação de modo a ser absolvido internamente.

Desta forma, a capacidade do receptor para fazer uso da informação transferida, parece ser outra grave limitação para a transferência de tecnologia. Isto requer uma análise mais vertical sobre o ambiente receptor, que precisa de uma relevante e responsiva infraestrutura cultural, institucional, pessoal, informacional e de mercado. Destarte, para ter êxito no seu objetivo principal de inovação, o que não tem sido comum entre PMEs, quem recebe a tecnologia precisa fazer investimentos e desenvolver estratégias e programas de educação e de desenvolvimento de habilidades para tal fim (BARBOSA; VAIDYA, 1995).

A pesquisa base deste artigo sugere a necessidade de se incluir na infra-estrutura necessária para a transferência de tecnologia serviços de informação para dar suporte tanto às atividades de transferência de tecnologia (entendida aqui como a transferência de conhecimento corporificado na tecnologia, nas pessoas, na organização e nos documentos) quanto ao próprio processo de inovação. Este último inclui a tomada de decisão, a seleção e a transferência do tangível (tecnologia), do know-how (conhecimento tácito) e de informação científica e tecnológica. Esta requer tratamento específico em termos de seleção, refinamento re-empacotamento, organização para recuperação, acesso e uso em tempo real, de modo a que o conhecimento codificado se torne mais fácil de ser absorvido e, assim,mais útil às empresas, como indicado no trabalho de Grant e Steele de 1995.

Os serviços de informação, desenvolvidos em uma eficiente plataforma de coleta e disseminação de informação entre pessoas, setores e nações, são sistemas de informação cuja integração deve se refletir no seu conteúdo e na sua função como canais de transferência de tecnologia. Em termos de conteúdo, ele se apresenta como um canal de comunicação de mão dupla entre a demanda e o suprimento de informação tecnológica, objetivando a disseminação rápida e eficaz dos resultados de sucesso de inovação tecnológica, de transferência de tecnologia e dos resultados das pesquisas científicas, disponibilizando informações para 
demandas técnicas e dificuldades das empresas e feedback de negócios para desenvolver tecnologias apropriadas em função das demandas de mercado.

Com relação à sua função, deve haver um constate esforço para melhorar a interação com o website dos usuários e no desenvolvimento de uma plataforma para popularizar os resultados de pesquisas científicas e informações técnicas de negócios, a partir da oferta de serviços de recuperação da informação e de projetos-chave, um serviço e informação em um novo nível como uma rede de tecnologia integrada com a nacional e regional.

As tentativas para transferir uma tecnologia de um laboratório ou universidade para o setor industrial é um processo complexo que envolve diversas organizações e vários profissionais-chave em cada organização, como a própria instituição de pesquisa, um ou mais organizações usuárias durante o desenvolvimento e teste do produto, uma agência de transferência (ex.: parque tecnológico), um agência de fomento pública, um receptor para a manufatura e uma agência de fomento privada. $\mathrm{O}$ estudo da referida pesquisa sobre os atores envolvidos na transferência sugere uma variedade de fatores interligados que contribuem para o sucesso ou falha da TT, sendo um deles a criação e/ou implementação de serviços de informação.

\section{CONSIDERAÇÕES FINAIS}

Este artigo buscou na análise das definições de transferência de tecnologia uma concepção mais holística de TT que a concebe como transferência de conhecimento incorporado a produtos, processos, pessoas, organizações e documentos. Considerou-se ser necessária uma definição mais dinâmica de TT para se discutir os serviços de informação como um canal de transferência, uma ponte a ser construída entre os dois lados do denominado "vale da morte" da ilustração de Irvine Peacock (apud AMI TECHNOLOGY TRASNFER EVENT, 2005) acerca das barreiras e limitações da transferência de tecnologia. Os serviços de informação funcionariam como canais gerenciadores de fluxos de informação científica e tecnologia entre a universidade e a indústria e facilitadores das relações entre estes dois segmentos.

Considerou-se que um entendimento mais abalizado de transferência de tecnologia, em especial entre a universidade e indústria, é fundamental para compreender o processo para além da transferência da tecnologia em si, mas envolve diferentes atores, habilidades e atividades. Assim, este estudo provê uma abordagem diferenciada de transferência de 
tecnologia, de uma simples transferência de conhecimento e tecnologia para enfatizar a relevância de um variado número de componentes fundamentais entre os quais se encontram os serviços de informação.

As concepções de transferência de tecnologia apresentadas neste artigo sugerem a existência de um processo comunicacional de transferência de conhecimento, proporcionando uma base mais consistente para se analisar o papel dos serviços de informação como um canal que tem sido negligenciado, mas que pode facilitar e melhorar o processo de transferência.

Nessa abordagem, uma análise dos diferentes tipos de conhecimento usados em uma empresa é necessária para testar a hipótese geral desta pesquisa: conhecimento formal (explícito), definido aqui como informação científica, tecnológica e empresarial. Este tipo de conhecimento pode ter um impacto mais positivo no processo de transferência de tecnologia, se o processo for apoiado por um serviço de informação especialmente projetado para selecionar, organizar, refinar e re-empacotar informação científica, tecnológica e empresarial, tornando-o mais absorvível e, assim, mais útil aos seus usuários finais.

Não se encontrou na literatura atual alteração significativa nos conceitos de transferência de tecnologia além daqueles tratados por diversos autores na década de 1990, em termos de inclusão dos serviços de informação nos discursos sobre transferência de tecnologia, merecendo ser mais investigado.

O estudo sugere, também, que para as universidades contribuírem para a competitividade da indústria e dela receber insumo para o incremento de seus projetos de pesquisa há necessidade de se construir pontes que favoreçam as ligações entre os dois setores, sendo os serviços de informação um canal-chave desse entendimento.

\section{NOTAS}

\footnotetext{
1 'Necessidades' e 'Desejos' são termos que têm significados diferentes que deveria ser levado em conta por qualquer serviço de informação. Serviços de informação normalmente são que tomam a decisão final tanto relativa à coleção de uma biblioteca, quanto às necessidades de informação do usuário. Raramente é discutido e considerado o quê os usuários necessitam e desejam.

2 São características do conhecimento tácito apresentado por Polanyi, 1966; Senker, 1993; Pavitt, 1998, Nonaka, 1994

${ }^{3}$ Compõem o conhecimento codificado e prático apresentado por Faulkner, 1994, Rebentish; Ferreti, 1993

${ }^{4}$ Dizem respeito à maquinaria - como visto por Barbosa e Vaidya, 1996.

${ }^{5}$ Veja especialmente Teece (1981), sobre a complexidade de capturar conhecimento para transferir, Collet, (1994), a respeito de know-how, e Rebentish e Ferreti (1993), sobre caminhos apropriados para capturar "knowhow".
} 


\section{REFERENCIAS}

ALMEIDA, Henrique S. de. Um estudo do vínculo tecnológico entre: pesquisa, engenharia, fabricação e consumo. 163 p. Tese de Doutoramento. Escola Politécnica, Universidade de São Paulo, 1981.

AUTIO, E. Tecnology transfer effects of new, technology-based companies: na empirical study. Helsinki: Helsinki University of Technology/Institute of Industrial Management; Espoo, 1993.

BARBOSA, F.; VAIDYA, K. G. Developing technological capabilities: the case of a Brazilian steel company, Technology Management: strategies and applications, v. 3, n.

3, p. 287-298,1996.

BESSANT, John; RUSH, Howard. Government support of manufacturing innovation: two countrylevel case study. IEEE Transactions of Engineering Management, v.40, n.1, p. 7991, Feb., 1993.

BIGELOW, Jacob. Elements of technology. Boston: Boston Press, 1829. p.iii-iv.

CARR Robert K.; HILL, Christopher T. R\&D and Technology Transfer in the United States: the least known piece of the puzzle: background paper for the Binational Panel of the National Academy of Engineering and German Fraunhofer Society. 1995. Washington, DC: National Academy Press, 1997.

COLLET, M. A. A contingency model of international manufacturing configuration. Paper presented at ORSA/TIMS, Oct. 1994 (fotocópia).

CORTI apud PERUSSI FILHO, Sergio. Uma avaliação da contribuição das cooperações universidade-empresa e inter-empresas para a competitividade das empresas industriais do pólo tecnológico de São Carlos. Tese (Doutorado Engenharia da Produção) Universidade de São Carlos, 2001. Disponível em:< http://www.teses.usp.br/teses/disponiveis/18/18140/tde-26042002-113324/>

CYSNE, M. R. Fátima Portela. Transferência de conhecimento entre a universidade e a indústria: serviços de informação para empresas de pólos tecnológicos.305fl. Tese (Doutorado em educação)- Faculdade de Educação. Universidade Federal do Ceará, 2003

DRUCKER, Peter F. Knowledge work and Knowledge Society: the social transformations of this Century. 1994.

. Trade lessons from the world economy. Foreign Affairs, v.73, n.1, p. 99-108, Jan/Feb 1994 . p. 151-176. Disponível em: http://www.millkern.com/rkcarr/fourth.html Post-Capitalist Society. Oxford: Butterworth Heinemann,1993.

DREYFUS, H.; DREYFUS, S. Mind over machine: the power of human intuition and expertise in the era of the computer. New York, The Free Press,1986.

FAULKNER, Wendy. Conceptualizing knowledge used in innovation: a second look at the science-technology distinction and industrial innovation. Science. Technology and Human Value, v.19, n.4, p. 425-458, Autumm, 1994.

FAULKNER, Wendy; SENKER, Jacqueline; VELHO, Léa. Science and technology knowledgeflows between industrial and public sector research: a comparative study. Brighton: SPRU: University of Sussex, 1993.

FREUND, Julian French (apud VOLTI, Rudi. Society and technological change. 3rd ed. [S.1.]: St. Martin's Press, 1995,

GILL, K. S. (Ed.), Human machine symbiosis: London: Springer, 1996.

GOVERNMENT WHITE PAPER. Realising Our Potential: Strategy for Science, Engineering and Technology. London: HMSO, 1993. 
GRANT, Elliot; STEELE, Andrew. International manufacturing transfer: linking context and process. Paper present at ICAM'95: Anthropocentric Lean Production System. Sunderland (UK), 11-13 Sep. 1995.

JEREMY, D. J. (Ed.). The transfer of international technology: Europe, Japan, and the USA in the twentieth century. Brookfield, VT: E. Elgar Pub, 1992.

NONAKA, I. A dynamic theory of organizational knowledge creation. Organization Science, v.5, n.1, p 14-37, 1994.

ODZA Michael.Technology Access Report. Technology Transfer Society. Disponível em: < http://millkern.com/washtts/definitions.html>

PATEL, P.; PAVITT, K. Patterns of technological activity: their measurement and interpretation. Handbook of the economics of innovation and technological change. P.Stoneman: Blackwel. 1995.

PAVITT, K. The social shape of the national science base. Research Policy, v. 27, n. 8, 1998p. 793-805

PEACOCK, Irvine AMI TECHNOLOGY TRANSFER EVENT. Framework of the Workshop, 2005. Disponível em:

$<$ http://www.amiproject.org/pdf/AMI_Technology_Transfer_Workshop_2005.pdf $>$

POLANYI, M. The tacit Dimension. Garden City, NY: Doubleday \& Co., 1966.

RANIS, G. (Ed.). Science and technology: lessons for development Policy. Boulder, REBENTISH, E. S; FERRETI, M. A knowledge asset-based view of technology transfer in international joint ventures. Cambridge, Mass.: Sloan School of Management, MIT, 1993. Working Paper 86-93

ROGERS, E. M. (1995). Diffusion of Innovations. $4^{\text {th }}$. Ed. New York: Free Press.

ROOD, Sally. Introduction to the Federal Laboratory Consortium. Washington World Intellectual Property Organization (WIPO). 2001. Microsoft Powerpoint 97.

ROSENBERG, N. Inside the black box: technology and economics. Cambridge: Cambridge University, 1982

SÁBATO, J. A.Transferencia de tecnología: una revisión bibliográfica. México: CEESTEM, 1978.

SANDIA NATIOANL LABORATORIES. A strong science, technology, and engineering heritage extends into the future. Sandia's Annual Report . Disponível em: < http://www.sandia.gov/mission/ste/index.html>

SENKER,Jacqueline.Thecontributionoftacitknowledgeto innovation. AI and Society, n.7, p. 208-224, 1993.

Tacit knowledge in Innovation. Brighton: SPRU.University of Sussex, 1991.

SPENCE, W. R. Innovation: the communication of change in ideas, practices and products. London: Chapman \& Hall, 1994.

STEWART, Frances. 1990. Technology Transfer for Development. In: EVENSON, R.; Colorado: Westview Press, 1990.

THE TECHNOLOGY TRANSFER SOCIETY, 2005. Disponível em $<$ http://millkern.com/washtts>

TEECE, D. J. The Market for know-how and the efficient international transfer technology. The Annual of American Academy of Political and Social Science, n.458, Nov. p. 81-96, 1981.

VOLTI, Rudi. Society and technological change. 3rd ed. New York: St. Martin's Press, 1995.

THE WASHINGTON AREA CHAPTER OF THE TECHNOLOGY TRANSFER SOCIETY, 2005. Disponível em: < http://millkern.com/washtts/> 
WHISTON, T. G. Education and employment for a sustainable world. In: FAST FOP 333, June 1992, FAST Programme, DGXII, Commission of the European Communities, 200 rue de la Loi, B-1049, Brussels.

\begin{abstract}
Conceptual approach of tecnology, inovation, and technology transfer between university and industry as the transfer of knowledge (tacit and codified), as a theoretical base to include information services as a relevant component for the success of technology transfer. Analyse of technology transfer process, as well as both mechanisms and actors involved in this process and the complexity of its implementation.
\end{abstract}

KEYWORDS: Technology Transfer. Technology. Technological Innovation. Knowledge Transfer. Information Services.

Originais recebidos em 18/04/2005. 